authorities to conduct crime scene investigations in the field to understand the poachers' mode of operation.

This information is not only relevant to criminal investigations but also to quantification of the impact of poaching on vicuña population dynamics and structure. Crime scene investigation uses techniques from various disciplines, including population ecology, anatomy, criminalistics and population genetics. Genotyping of individual carcasses found at a crime scene facilitates tracking of the origin of pelts seized from the black market. There is still a need, however, to develop standardized protocols for forensic entomology and taphonomy, for determining the cause of and time since death.

The study of vicuña carcasses with crime scene investigation techniques was discussed at the XVIII Reunión Técnica del Convenio de la Vicuña held in Chile on the 22 September 2015, at which international delegates promised full cooperation and support to control poaching. Delegates also pledged to participate in the crime scene investigation workshops that will be led by Chilean officials trained in crime scene investigation techniques. This will be the first time that such strategies, protocols and international cooperation have been implemented in Latin America, where wildlife forensic science is still in its infancy.

Benito A. GonZÁlez Laboratorio de Ecología de Vida Silvestre, Departamento de Gestión Forestal y su Medio Ambiente, Facultad de Ciencias Forestales y de la Conservación dela Naturaleza, University of Chile, Santiago, Chile, and IUCN Species Survival Commission South American Camelids Specialist Group

E-mail bengonza@uchile.cl

JuAN Carlos Marín Laboratorio de Genómica y Biodiversidad, Departamento de Ciencias Básicas, Facultad de Ciencias, University of Biobío, Chillán, Chile

Victor Toledo Laboratorio de Anatomía, Departamento de Patología Animal, Facultad de Ciencias Veterinarias y Pecuarias, University of Chile, Santiago, Chile

EDGARD ESPINOZA National Fish and Wildlife Forensic Laboratory, Fish and Wildlife Service, Ashland, Oregon, USA

\section{Capacity building to conserve African otters}

There are 13 species of otter, 12 of which are known to be declining. In Africa otters are often overlooked, with attention directed towards other, high-profile, mammal species. There are three otter species in sub-Saharan Africa: the spotted-necked Hydrictis maculicollis (formerly Lutra maculicollis), African clawless Aonyx capensis and Congo clawless Aonyx congicus otters. In 2015 all three species were categorized as Near Threatened on the IUCN Red List of Threatened Species. The assessment process highlighted the lack of recent information, with much data over 25 years old.

Many of the issues facing otters, such as habitat loss, pollution, climate change and problems driven by poverty, are common to other species. Otters also face conflict with fishermen and are hunted for fur and for use in traditional medicine. But the main problem for otter conservation is lack of awareness and the resultant paucity of funding available for research, education and conservation.

During 20-25 July 2015 the International Otter Survival Fund organized the first Pan-African training workshop at the College of Wildlife Management, Mweka, Tanzania. The aim was to train participants in field techniques, public awareness programmes, law enforcement and general conservation issues, through classroom studies, discussion and practical field work. Participants came from Benin, The Gambia, Ghana, Democratic Republic of Congo (DRC), Ethiopia, Kenya, Malawi, Rwanda, South Africa and Tanzania. Some attendees were already working with otters through research or community work, as park rangers or ecologists or in associated fields such as wetland protection.

During the workshop Rita Chapman, Lubama Delphin Kumbi and Mubuma Chico Lunko from DRC gave a presentation about the rescue, rearing and release during 20102012 of two Congo clawless otter cubs. These otters became ambassadors for the Kikongo Otter Sanctuary in DRC, which is dedicated to conserving otters and raising awareness in the local community. These experiences provided insights into how to work with communities who may encounter impacts of otters on fishing.

The workshop identified long- and short-term goals for future work. As research alone is not conservation yet all programmes must be founded on sound scientific data, the workshop identified four goals: (1) develop projects to gather data on otter distribution, behaviour and threats, (2) share such data and experience through an active African otter network, (3) develop education material appropriate to community needs that can also be shared through the network, and (4) use social media to generate more awareness of otters and their importance in ecosystems.

To improve public awareness a Facebook page (www. facebook.com/AfricanOtter1?fref=ts) has been established for posting photographs of African otters and their signs, with a link to a confidential form for more detailed location information. The page is linked to the website of the International Otter Survival Fund (www.otter.org) and to the African Otter Outreach Project (www.facebook.com/ pages/African-Otter-Outreach-Project/181450325232204? fref=ts). An invitation-only online forum has been created for people to share experiences and to seek help and share education tools, and a second African Otter Workshop is 
planned for 2017, in another region of Africa so as to facilitate attendance from other nations.

New data are already being received. In 2005 a possible spotted-necked otter spraint was found at Lake Manyara, Tanzania, and the occurrence of the species there has now been confirmed by a sighting in 2015. Spotted-necked otters have also been seen at Lake Kivu in Rwanda, and otter signs have been found at Liparamba Game Reserve, Tanzania, although as yet the species has not been confirmed.

The workshop was funded by the Anderson-Rogers Foundation, the Animal Defence Trust, Columbus Zoo, the Rufford Maurice Laing Foundation, Sacramento Zoo and private donors.

Hugues AKPONA Université d'Abomey-Calavi, Cotonou, Benin

JAN REED-SMITH African Otter Outreach Project, Lake Odessa, Michigan, USA

GRACE YoXon International Otter Survival Fund, Skye, UK Email grace@otter.org

\section{Increasing exploitation of grey parrots in eastern DRC drives population declines}

In 2012 the grey parrot Psittacus erithacus was categorized as Vulnerable on the IUCN Red List of Threatened Species as a result of ongoing population declines driven by the global captive bird trade and habitat loss. Although the majority of range states have now ceased export of grey parrots, Cameroon and the Democratic Republic of Congo (DRC) maintain export quotas agreed under Annex II of CITES.

DRC has emerged in recent years as the largest exporter of wild-caught grey parrots. Data from Maniema and Orientale provinces indicate surging levels of exploitation since 2010, with increased trapping driving population declines. The trade in parrots is solely for export. Numbers of birds shipped indicate that CITES export quotas are probably being dramatically exceeded.

Monitoring of grey parrot aggregations in the region's Tshuapa-Lomami-Lualaba landscape was initiated by the Lukuru Foundation and the Congolese Institute for Nature Conservation in 2010. Monitoring includes surveys of communal nesting areas, roosts and forest clearings where birds descend to ingest soil and water. Interviews with 20 trappers and traders have been conducted to date, with 56 direct observations of trapping, purchase and transport of captured birds. Since 2013 air shipment data have been collected at the provincial trading hubs of Kisangani and Kindu.

Since 2010, 12 of 18 known parrot aggregations within the monitored area have been exploited by trappers. Parrot numbers have declined at five of these aggregations since 2012. Trappers abandoned three exploited sites, first monitored in 2013, after parrot numbers collapsed. This includes a nesting area that had previously been lightly harvested by local communities for 35 years.

The recent increase in trapping is driven by the arrival of trappers and traders from outside the area. In 2015 six aggregations were exploited for the first time. All were exploited by teams coming into the area from other provinces, where they reported declining yields in previously exploited areas. This suggests that increasing exploitation in eastern DRC is part of a wider phenomenon of unsustainable harvesting in the region.

Parrots are shipped from Kisangani and Kindu to agents based primarily in Kinshasa who then export the birds. Shipping records suggest that exports probably exceed the annual national CITES quota of 5,000 individuals. Recorded air shipments from Kindu and Kisangani over a 4-month period (May-August) in 2015 indicate a minimum of 6,632 birds were shipped from the two cities, averaging $>400$ per week.

Current regulations are failing to control trade and are leading to unsustainable exploitation. Although some of the country's wildlife regulations are propagated at the national level, management of fauna is decentralized to the provinces. Maniema and Orientale provinces were unprepared for the massive increase in parrot exploitation. They have responded, however, to reports on the impact of the trade. On 7 August 2015 Maniema's environment ministry imposed a 6-month moratorium on captures, including a ban on all air shipments from Kindu. Both Maniema and Orientale have asked for assistance to monitor aggregations, and both provinces are considering proposals to protect important aggregations.

Provincial efforts to manage parrots will require significant international support. Management is unlikely to be effective if international demand for wild-caught parrots remains unchecked. There is a need for an immediate moratorium on exports of grey parrots from DRC.

John Hart, Terese Hart, Leon Salumu, AndRew Bernard and RoBert ABANI Lukuru Foundation, Kinshasa, Democratic Republic of the Congo

Rowan MARTIN World Parrot Trust, Hayle, Cornwall, UK, and Percy FitzPatrick Institute of African Ornithology, University of Cape Town, Cape Town, South Africa E-mail rowan.o.martin@gmail.com

\section{Recent advances in combating illegal ivory trade in China}

Illegal trade in wildlife and wildlife products, in particular ivory trafficking, continues to pose a threat to the survival 